\title{
UM BANHO TERMOSTÁTICO DE BAIXO CUSTO (TEMPERATURA AMBIENTE ATÉ 0C)
}

\author{
Cristina M. Quintella*, Cristiane C. Gonçalves, Ângelo M. V. Lima, Alexandre K. Guimarães e José C. dos Santos \\ Instituto de Química, Universidade Federal da Bahia, Campus de Ondina, 40170-290 Salvador - BA \\ Iuri M. Pepe \\ Instituto de Física, Universidade Federal da Bahia, Campus de Ondina, 40170-290 Salvador - BA
}

Recebido em 21/12/01; aceito em 24/7/02

\begin{abstract}
A LOW COST THERMAL BATH (ROOM TEMPERATURE TO $0{ }^{\circ} \mathrm{C}$ ). Thermal baths to decrease ambient temperature are an indispensable tool for most research and teaching laboratories, especially those in tropical or equatorial regions. A simple and inexpensive thermal bath has been developed based on a scratched compressor. It has three possible setups for cooling: sample immersed into the bath, sample flowing through the bath, and cooling liquid flowing in a jacket around the sample. It has been tested for 40 months. The temperature ranges from room temperature to $0{ }^{\circ} \mathrm{C}$, when using water. The repeatability is better than $3 \%$ and the precision varies from $0.5 \%$ to $2 \%$.
\end{abstract}

Keywords: thermostatization; instrumentation for chemistry laboratories; thermal bath.

\section{INTRODUÇÃO}

Os processos e reações químicas são, em geral, dependentes da temperatura. Assim banhos termostáticos, apesar de muito simples, tornam-se ferramenta indispensável para laboratórios tanto de ensino como de pesquisa.

Grande parte dos dados tabelados em manuais e compêndios de química, utilizados para comparação e calibração de práticas de ensino, controle de experimentos e validação de dados de pesquisa foram obtidos em países de climas frios ou temperados. Neles as temperaturas estão, na maior parte do ano, abaixo de $20^{\circ} \mathrm{C}$ e, para alcançar faixas de temperatura de $5{ }^{\circ} \mathrm{C}$ a $20^{\circ} \mathrm{C}$, é necessário realizar o aquecimento do sistema estudado. Já na maioria do território brasileiro e da América do Sul, as temperaturas são mais elevadas durante a maior parte do ano ou até durante o ano inteiro (que é o caso das regiões Norte e Nordeste do Brasil). Para alcançar a mesma faixa de temperatura, torna-se necessário resfriar os sistemas. Adicionalmente, várias técnicas de investigação requerem temperaturas inferiores à ambiente, de modo a observar cinética e equilíbrios químicos e melhorar a razão sinal/ruído.

É importante ressaltar que, em geral, no Norte e Nordeste do Brasil os centros de ensino público estaduais e federais não têm em seus laboratórios didáticos banhos termostáticos refrigerantes, à exceção de algumas poucas universidades federais ou de unidades particulares de ensino.

Banhos termostáticos que operem apenas entre $0{ }^{\circ} \mathrm{C}$ e $25^{\circ} \mathrm{C}$ não fazem parte dos catálogos usuais das empresas de equipamentos para laboratório. Elas vendem banhos mais complexos, que podem custar entre US\$1.000,00 e 6.000,00 a depender da sua especificidade. Nem sempre tal montante está disponível para aquisição. Além disto, como a maioria dos banhos utilizados em laboratórios de química são importados, não só não estão disponíveis para entrega imediata, como também, quando apresentam problemas de ordem técnica, é difícil encontrar peças de reposição e mão de obra especializada para sua manutenção ${ }^{1}$.

Uma solução apresentada na literatura para a termostatização de sistemas de análise por injeção de fluxo (FIA) foi proposta por

*e-mail: cristina@ufba.br
Lehmkuhl et al. ${ }^{2}$. Neste artigo é descrito um engenhoso sistema de resfriamento do percurso analítico. A amostra passa num tubo interno, sendo termostatizada por um líquido refrigerante que circula numa camisa. Neste trabalho a solução apresentada é a termostatização indireta da amostra estudada, não sendo apresentados maiores detalhes sobre o banho térmico que alimenta o sistema de camisa.

Foi também relatado por de Oliveira et al. ${ }^{1}$ o desenvolvimento de um banho termostático para aplicações em sistemas reacionais orgânicos e em resfriamento de sistemas de vácuo. Apesar da inovação da idéia proposta, o sistema apresentado funciona apenas em duas temperaturas fixas $\left(-40^{\circ} \mathrm{C}\right.$ ou $\left.-60{ }^{\circ} \mathrm{C}\right)$, sendo o calor do sistema estudado retirado por um dedo frio metálico, que fica em contato com a amostra.

Neste texto é apresentado o desenvolvimento e o desempenho de um banho termostático, para resfriamento e controle de temperatura, funcionando entre $0{ }^{\circ} \mathrm{C}$ e a temperatura ambiente. $\mathrm{O}$ equipamento foi construído a partir de um bebedouro desativado, com valor final de $\mathrm{R}$ \$285,00 (cerca de US\$160,00 à época de sua construção) e vem funcionando, de maneira satisfatória, há cerca de 40 meses. Sua construção é simples, prática e barata.

\section{PARTE EXPERIMENTAL}

\section{Construção}

O banho termostático (Figura 1) é constituído de um compressor/condensador reaproveitado, uma caixa de isopor para conservação de bebidas e alimentos e um termostato, sendo todo montado sobre uma base metálica.

O compressor (C1) modelo PW 3.5 da Embraco $(110 \mathrm{~V} / 60 \mathrm{~Hz})$ e seu respectivo condensador $(\mathrm{C} 2)$ foram retirados de um bebedouro alienado e recuperados em uma oficina de reparo e prestação de serviços de resfriamento. O seu fluido refrigerante (R12 ou R134a) se expande numa serpentina de cobre ( $\mathrm{S} 1)$, de $5 / 16$ polegadas, que se encontra mergulhada no reservatório $(\mathrm{R})$ com isolamento térmico. $\mathrm{O}$ tubo de cobre e suas conexões foram adquiridos em lojas de componentes para geladeiras e fogões.

$\mathrm{O}$ reservatório $\mathrm{R}$ consiste numa caixa de isopor revestida por polietileno que foi adquirida no comércio grossista local. Foi preen- 


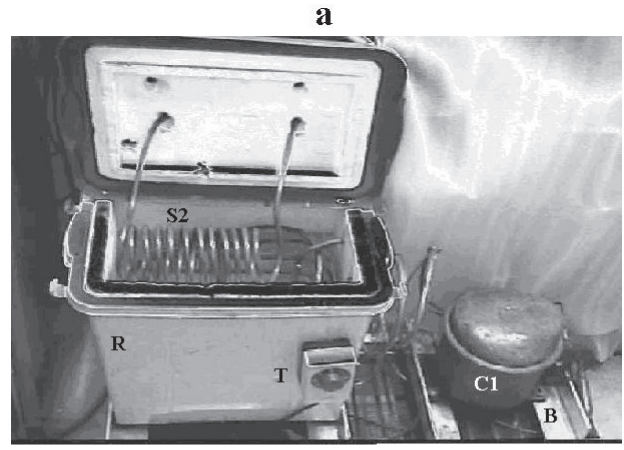

b

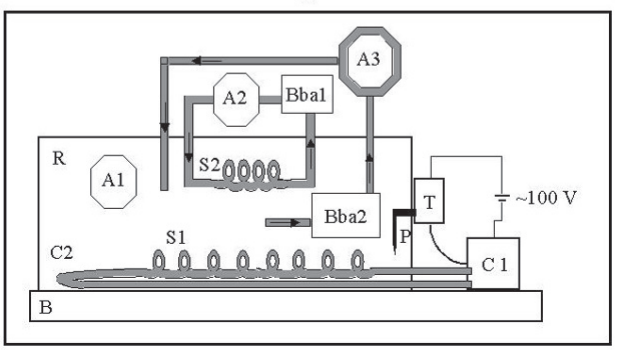

Figura 1 Banho desenvolvido para resfriamento e controle de temperatura: a) Foto; b) Esquema. ( $R$ ) reservatório com isolamento térmico; $(B)$ base do banho termostático (C1) compressor; (C2) condensador; (S1) serpentina de cobre do fluido resfriador; $(T)$ termostato; $(P)$ sensor de temperatura do termostato. São mostradas três montagens: (A1) amostra colocada dentro do banho; (A2) amostra em fluxo passa pela serpentina interna ao banho (S2), sendo bombeada pela bomba externa (Bba1); (A3) utilização do próprio líquido do banho, bombeado por uma bomba submersa (Bba2), para resfriar diretamente o sistema a ser estudado

chido com água, uma vez que a temperatura mínima requerida era de $0{ }^{\circ} \mathrm{C}$. Caso sejam necessárias temperaturas inferiores (até $-30{ }^{\circ} \mathrm{C}$ ) pode-se utilizar outro líquido ou uma mistura de duas ou mais substâncias. Foi escolhido um reservatório grande de 15 litros (dos quais 7 litros são preenchidos com água) por ser necessário que a capacidade do banho em absorver o calor seja alta, visto estar resfriando sistemas aquecidos por laser de argônio contínuo com potência de até 6 Watts. No caso de não ser necessária a absorção de grande quantidade de calor, o peso do banho pode ser reduzido, diminuindo-se o seu tamanho ou a quantidade de água no reservatório.

O reservatório possui uma segunda serpentina interna de cobre (S2), fixa e com 1/4 polegadas de diâmetro, com entrada e saída lateral, por onde passam as amostras líquidas em fluxo a serem termostatizadas.

O termostato (T), modelo UT71 da Danfus, com precisão de $0,25{ }^{\circ} \mathrm{C}$ e operando de $-30{ }^{\circ} \mathrm{C} \mathrm{a}+30{ }^{\circ} \mathrm{C}$, foi adquirido numa casa de material para refrigeração. $\mathrm{O}$ sensor $\mathrm{P}$ utilizado, já incorporado ao termostato, é um termômetro a gás com paletas metálicas que funcionam ao mesmo tempo como eletrodos de conexão com a rede elétrica e como interruptor. A extremidade do sensor encontra-se imersa no banho e funciona como uma chave de acionamento para o compressor, i. e., quando a temperatura aumenta ele liga o compressor, desligando-o quando a temperatura desce abaixo do valor programado.

A base do banho (B) tem a dupla função de, por um lado, dissipar o calor gerado pelo compressor e, por outro, servir de suporte ao banho, permitindo seu transporte fácil e seguro. Consiste de cantoneiras de alumínio soldadas entre si e a base utilizada permite a montagem sobre rodas, facilitando seu transporte.

Os tubos por onde circulam as amostras líquidas, a serem resfriadas, foram termicamente isolados, fazendo com que a estabilidade e a regulação de temperatura neste ponto do circuito contribuam para melhorar a estabilidade da temperatura das amostras.

Dada a sua versatilidade é possível resfriar diferentes montagens de amostras:

- amostra colocada dentro do banho (A1 na Figura 1);

- amostra em fluxo passando pela serpentina interna ao banho (A2 na Figura 1);

- utilização do próprio líquido do banho, bombeado por uma bomba submersa, permite resfriar diretamente o sistema a ser estudado (A3 na Figura 1).

\section{Lista de material}

O investimento na confecção do banho termostático foi de $\mathrm{R} \$$ 285,00 , sendo $\mathrm{R} \$ 150,00$ para mão de obra e $\mathrm{R} \$ 135,00$ de peças. A Tabela 1 lista os diversos componentes utilizados, sugere onde adquiri-los e seu preço típico.

\section{Avaliação do desempenho}

É importante salientar que o circuito por onde passa a amostra líquida não é simples, vários e diferentes materiais foram usados em sua montagem. Sendo assim, têm que ser levadas em consideração as transferências térmicas entre o líquido e os tubos de cobre (S1 e S2). Este conjunto, após $150 \mathrm{~min}$ atinge o equilíbrio térmico e a oscilação média da temperatura é de $\pm 0,3{ }^{\circ} \mathrm{C}$.

A Figura 2a mostra uma das curvas obtidas no monitoramento da temperatura do sistema banho - amostra circulante. Quando o sistema de resfriamento foi acionado, o banho encontrava-se à temperatura ambiente, ou seja, $24 \pm 1^{\circ} \mathrm{C}$.

A Figura $2 \mathrm{~b}$ mostra o intervalo de confiança (barra de erro) para o controle de temperatura em torno de uma temperatura central (círculo vazio). A precisão de regulação varia entre 0,5 e $2 \%$, tendo sido determinada a partir de medidas feitas com um multímetro/termômetro digital TES 2730 tanto imerso no banho, quanto em contato com a amostra a ser resfriada. A repetibilidade foi determinada por vinte medidas sucessivas, para cada uma das diferentes temperaturas de regulação, sendo melhor que $3 \%$.

Tabela 1. Componentes do banho termostático com sugestões de local onde adquirir e custo típico

\begin{tabular}{llr}
\hline COMPONENTE & SUGESTÃO DE LOCAL ONDE OBTER & CUSTO (R\$) \\
\hline Compressor e seu condensador & Equipamento desativado (bebedouro, ar condicionado, geladeira, congelador) & Zero \\
Termostato & Loja de material para refrigeração & 45,00 \\
Base metálica & Loja de ferragens & 30,00 \\
Tubos de cobre e conexões & Loja de peças para fogões & 30,00 \\
Caixa de isopor & Supermercados & 30,00 \\
\hline TOTAL & & 135,00 \\
\hline
\end{tabular}



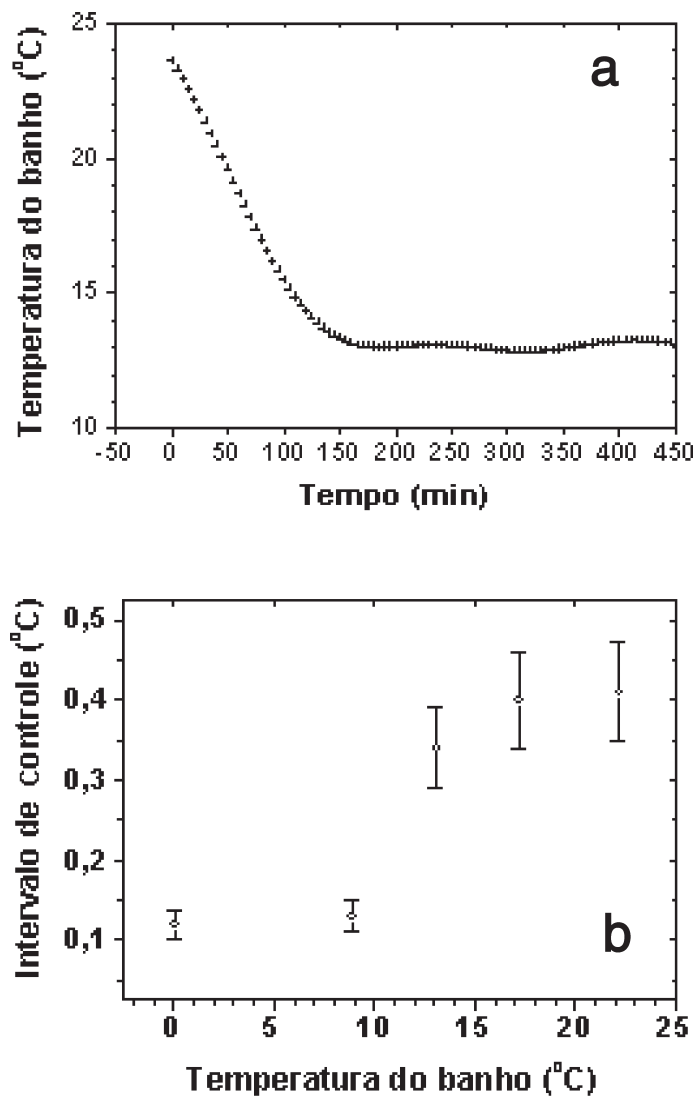

Figura 2 Curvas de desempenho do banho termostático: a) Curva típica da variação de temperatura com o tempo; $b$ ) Intervalo de controle (margem de erro) para várias temperaturas (círculos)
A regulação das temperaturas mais baixas, onde a diferença em relação à temperatura ambiente é maior, é nitidamente melhor, como aliás era de se esperar, uma vez que o tempo em que o compressor fica ligado é maior. Pequenas variações nesse tempo (tipicamente $5 \%)$ perturbam muito pouco a temperatura final $(0,3 \%)$. Além disto, perto de $0{ }^{\circ} \mathrm{C}$, o calor latente de mudança de estado da água contribui para a estabilidade da temperatura do banho.

\section{CONCLUSÕES}

O banho desenvolvido para resfriamento e controle de temperatura está funcionando há 40 meses, sem necessidade de manutenção. Sua facilidade de transporte faz com que ele possa ser utilizado em diversos experimentos num mesmo laboratório ou em laboratórios vizinhos.

Sua versatilidade já permitiu a utilização em diversas aplicações (viscosidade, tensão superficial, condutividade de soluções de surfactantes, dados reológicos, mapeamento de fluorescência total em função da temperatura, anisotropia de amostras líquidas estáticas e de fluxos líquidos).

O equipamento oferece precisão satisfatória e seu custo permite a montagem sem que a unidade de pesquisa e/ou ensino tenha que fazer grande investimento.

\section{AGRADECIMENTOS}

Os autores agradecem ao Programa de Pós-Graduação do Instituto de Química pelo financiamento; ao CNPq pela bolsas de iniciação científica de A. M. V. Lima e pela bolsa de produtividade em pesquisa de C. M. Quintella.

\section{REFERÊNCIAS}

1. de Oliveira, A. R. M.; Simonelli, F.; Marques, F. A.; dos Santos, A. A.; Pereira, G. A.; Assenheimer, O.; Quim. Nova 1997, 20, 673.

2. Lehmkuhl, A.; Ganzarolli, E. M.; de Souza, I. G.; Nome, F.; Quim. Nova 1999, 22, 136. 